Editorial

\title{
Special Issue: Application of Advanced Oxidation Processes
}

\author{
Ciro Bustillo-Lecompte ${ }^{1, * \mathbb{D}}$, Jose Colina-Marquez ${ }^{2, * \mathbb{D}}$ and Lars Rehmann ${ }^{3, * \mathbb{D}}$ \\ 1 School of Occupational and Public Health, Ryerson University, 350 Victoria Street, Toronto, \\ ON M5B 2K3, Canada \\ 2 Department of Chemical Engineering, Universidad de Cartagena, Sede Piedra de Bolívar, Avenida del \\ Consulado 48-152, Cartagena 130015, Colombia \\ 3 Department of Chemical and Biochemical Engineering, Western University, \\ Thompson Engineering Building, London, ON N6A 5B9, Canada \\ * Correspondence: ciro.lecompte@ryerson.ca (C.B.-L.); jcolinam@unicartagena.edu.co (J.C.-M.); \\ lrehmann@uwo.ca (L.R.)
}

Received: 16 July 2020; Accepted: 16 July 2020; Published: 18 July 2020

Advanced oxidation processes (AOPs) are nowadays not only considered as a complementary treatment option but as an attractive alternative to conventional methods. AOPs are often used to improve the biodegradability of wastewaters, as well as in the inactivation of pathogenic microorganisms. This Special Issue focuses on the "Application of Advanced Oxidation Processes" and covers recent progress and trends in AOPs. A total of eleven papers constitute this Special Issue, covering different aspects of the application of AOPs. Three review papers provide comprehensive appraisals on the state-of-the-art of AOPs in industrial applications, while eight research papers cover specific technologies for wastewater treatment, dye decolorization, and nanotechnology applications.

The first review explores different photocatalytic processes used for the treatment of gold mining wastewater with an emphasis on cyanide wastewater applications [1]. In this review, Betancourt-Buitrago et al. [1] investigate the effectiveness of photocatalytic processes in the removal of free cyanide via oxidative pathways, where the need for more studies-with respect to the presence of complexed cyano-metallic compounds in photoreactors, the requirement of modifying selectivity using electron donors as scavengers of unwanted radicals, as well as the use of unconventional UV LED lamps as a growing field in photoreactors design-is highlighted.

The second review summarizes the advantages and disadvantages of different treatment methods of spent caustic wastewater from the mercaptan oxidation process in the oil industry [2]. Moreover, Pino-Cortés et al. [2] describe the characteristics of spent caustic and its environmental impacts, followed by an analysis of current neutralization processes to improve biodegradability.

The last review by Ramírez Orejel and Cano-Buendía [3] highlights the advantages of using electrolyzed water in the food industry. The authors describe the characteristics of electrolyzed water and explore the main applications of electrolyzed water in the food industry, specifically in animal products derived from poultry, cattle, swine, and fish for sanitation, cleaning and disinfection.

The first of the eight research papers presented in this Special Issue examines the effect of heating oxidation on the surface/interface features and floatability of anthracite [4]. The changes in surface and interface of coal particles were confirmed by Rong et al. [4] using scanning electron microscopy (SEM), Fourier-transform infrared spectroscopy (FTIR), and X-ray photoelectron spectroscopy (XPS).

The second research paper explores the potential of cow manure to produce highly porous activated carbon $(\mathrm{AC})$ using a potassium hydroxide $(\mathrm{KOH})$ activation process at different temperatures for the removal of methylene blue from an aqueous solution [5]. Based on the XPS and FTIR observations, Tsai et al. [5] concluded that the AC from cow manure has a strong interaction with the cationic 
compound (i.e., methylene blue) due to its large pore properties and oxygen-containing complexes on the surface.

The following two research papers are related to nanotechnology applications. Leybo et al. [6] investigated the effect of ferric and ferrous salts on the structural characteristics and physicochemical properties of nanoscale zero-valent iron samples synthesized by borohydride reduction. Samples were characterized by SEM, transmission electron microscopy, X-ray diffraction, and low-temperature nitrogen adsorption. Leybo et al. [6] showcase the synergistic action of nanoscale zero-valent iron and ferrihydrite leading to higher $\mathrm{Pb}^{2+}$ ion removal from water via borohydride reduction of iron from sulphate salt.

On the other hand, Hou et al. [7] synthesized mesoporous Mn-doped Fe/rGO nanocomposites by a co-precipitation method and investigated the ultrasonic-assisted removal of ethyl violet (EV) from synthetic wastewater. Artificial Intelligence (AI) models were combined with response surface methodology (RSM) to optimize the removal efficiency of Mn-doped Fe/rGO nanocomposites for EV. The Mn-doped Fe/rGO nanocomposite demonstrated its potential for the removal of dyes in water due to its facile synthesis, large adsorption capacity, high specific surface area, and excellent magnetic properties [7].

The last four research papers cover specific technologies for wastewater treatment and dye decolorization. The study by Chiliquinga et al. [8] explores the simultaneous production of the ferrate ion and free radicals on a boron-doped diamond (BDD) anode surface. Further, it examines the generation of both species in two different electrolytes with the addition of different concentrations of iron sulphate, and the effect of the current density on the degradation of a textile dye. Results showed fast degradation rates of up to $98 \%$ of colour reduction in $60 \mathrm{~min}$ of treatment with a COD reduction of over $60 \%$ [8].

Similarly, Lozano-Morales et al. [9] evaluated the photocatalytic degradation of nanostructured $\mathrm{TiO}_{2}$ catalysts under UV-C radiation and the effect of the $\mathrm{pH}$ of paracetamol suspensions on the overall degradation efficiency. The photocatalytic oxidation degraded up to $99 \%$ of the paracetamol at a $\mathrm{pH}$ of 6.5 , a value at which adsorption was favoured, leading to higher efficiency and exposure times below $100 \mathrm{~min}$, where no traces of metabolites were detected [9].

Another study explores the use of UV-activated free chlorine and investigates the degradation efficiency of the Aqueous Polycyclic Musk Tonalide [10]. Besides, Wang and Liu [10] identified primary contributors and intermediates, described the toxicity profile of the Aqueous Polycyclic Musk Tonalide, and evaluated the influence of natural organic matter, common anions and cations in the degradation.

Finally, the study by Sun et al. [11] compared $\mathrm{UV} / \mathrm{O}_{3}, \mathrm{US} / \mathrm{O}_{3}$, and $\mathrm{UV} / \mathrm{US} / \mathrm{O}_{3}$ processes based on the digestion time and conversion rate of standard $\mathrm{N}$-compounds, and investigated the influence of temperature, $\mathrm{pH}$, the concentration of $\mathrm{O}_{3}$, mass flow rate, UV intensity, US frequency, and power on digestion efficiency. Results showed that the $\mathrm{UV} / \mathrm{US} / \mathrm{O}_{3}$ process had the best digestion efficiency under optimum conditions of $\mathrm{pH}=11, \mathrm{O}_{3}$ mass flow rate of $3200 \mathrm{mg} / \mathrm{h}$, reaction temperature of $30{ }^{\circ} \mathrm{C}$, digestion time of $25 \mathrm{~min}, 18 \mathrm{~W}$ UV lamp power, $20 \mathrm{kHz}$ and $75 \mathrm{~W}$ of US frequency and power, respectively, for a wastewater conversion rate over $99 \%$ and total dissolved nitrogen in the range of $1.0-4.0 \mathrm{mg} / \mathrm{L}$.

These diverse contributions provide sustained evidence of the large variety of applications of AOPs as well as demonstrating a promising future of the research fields of photocatalysis, $\mathrm{UV} / \mathrm{O}_{3}$, electrochemical oxidation, sonolysis, nanotechnology in AOPs, the development of novel catalytic material, heating oxidation, UV-activated free chlorine, electrolyzed water, industrial wastewater treatment, and resource recovery, among other applications.

To conclude, the guest editors would like to thank all the authors for their valuable contributions; their efforts and contributions are highly appreciated. State-of-the-art applications of AOPs presented in this Special Issue may serve as valuable references for future research in this ever-evolving field. 
Author Contributions: Writing-review \& editing, C.B.-L., J.C.-M., and L.R. All authors have read and agreed to the published version of the manuscript.

Acknowledgments: The guest editors would like to acknowledge the authors who collaborated and contributed with their research towards this Special Issue.

Conflicts of Interest: The authors declare no conflict of interest.

\section{References}

1. Betancourt-Buitrago, L.; Hernandez-Ramirez, A.; Colina-Marquez, J.; Bustillo-Lecompte, C.; Rehmann, L.; Machuca-Martinez, F. Recent Developments in the Photocatalytic Treatment of Cyanide Wastewater: An Approach to Remediation and Recovery of Metals. Processes 2019, 7, 225. [CrossRef]

2. Pino-Cortés, E.; Montalvo, S.; Huiliñir, C.; Cubillos, F.; Gacitúa, J. Characteristics and Treatment of Wastewater from the Mercaptan Oxidation Process: A Comprehensive Review. Processes 2020, 8, 425. [CrossRef]

3. Ramírez Orejel, J.; Cano-Buendía, J. Applications of Electrolyzed Water as a Sanitizer in the Food and Animal-By Products Industry. Processes 2020, 8, 534. [CrossRef]

4. Rong, G.; Xu, M.; Wang, D.; Gui, X.; Xing, Y. Effect of Heating Oxidation on the Surface/Interface Properties and Floatability of Anthracite Coal. Processes 2019, 7, 345. [CrossRef]

5. Tsai, W.; Huang, P.; Lin, Y. Reusing Cow Manure for the Production of Activated Carbon Using Potassium Hydroxide (KOH) Activation Process and Its Liquid-Phase Adsorption Performance. Processes 2019, 7, 737. [CrossRef]

6. Leybo, D.; Tagirov, M.; Arkhipov, D.; Permyakova, E.; Kolesnikov, E.; Kuznetsov, D. Effect of Initial Salt Composition on Physicochemical and Structural Characteristics of Zero-Valent Iron Nanopowders Obtained by Borohydride Reduction. Processes 2019, 7, 769. [CrossRef]

7. Hou, Y.; Qi, J.; Hu, J.; Xiang, Y.; Xin, L.; Wei, X. Mesoporous Mn-Doped Fe Nanoparticle-Modified Reduced Graphene Oxide for Ethyl Violet Elimination: Modeling and Optimization Using Artificial Intelligence. Processes 2020, 8, 488. [CrossRef]

8. Chiliquinga, M.; Espinoza-Montero, P.; Rodríguez, O.; Picos, A.; Bandala, E.; Gutiérrez-Granados, S.; Peralta-Hernández, J. Simultaneous Electrochemical Generation of Ferrate and Oxygen Radicals to Blue BR Dye Degradation. Processes 2020, 8, 753. [CrossRef]

9. Lozano-Morales, S.; Morales, G.; López Zavala, M.; Arce-Sarria, A.; Machuca-Martínez, F. Photocatalytic Treatment of Paracetamol Using $\mathrm{TiO}_{2}$ Nanotubes: Effect of $\mathrm{pH}$. Processes 2019, 7, 319. [CrossRef]

10. Wang, L.; Liu, X. Degradation of Aqueous Polycyclic Musk Tonalide by Ultraviolet-Activated Free Chlorine. Processes 2019, 7, 95. [CrossRef]

11. Sun, X.; Chen, H.; Liu, Z.; Zhou, M.; Cai, Y.; Pan, H.; Xia, L. Investigations on Ozone-Based and UV/US-Assisted Synergistic Digestion Methods for the Determination of Total Dissolved Nitrogen in Waters. Processes 2020, 8, 490. [CrossRef]

(C) 2020 by the authors. Licensee MDPI, Basel, Switzerland. This article is an open access article distributed under the terms and conditions of the Creative Commons Attribution (CC BY) license (http://creativecommons.org/licenses/by/4.0/). 